\title{
Relative impact of maternal depression and associated risk factors on offspring psychopathology
}

\author{
Edward D. Barker, William Copeland, Barbara Maughan, Sara R. Jaffee and Rudolf Uher
}

\section{Background}

In general, mothers with depression experience more environmental and family risk factors, and lead riskier lifestyles, than mothers who are not depressed.

\begin{abstract}
Aims
To test whether the exposure of a child to risk factors associated with mental health adds to the prediction of child psychopathology beyond exposure to maternal depression.
\end{abstract}

\section{Method}

In 7429 mother-offspring pairs participating in the Avon Longitudinal Study of Parents and Children in the UK, maternal depression was assessed when the children were aged 1.5 years; multiple risk factor exposures were examined between birth and 2 years of age; and DSM-IV-based externalising and internalising diagnoses were evaluated when the children were 7.5 years of age.

\section{Results}

Children of clinically depressed mothers were exposed to more risk factors associated with maternal mental health. Maternal depression increased diagnoses of externalising and internalising disorders, but a substantial portion of these associations was explained by increased risk factor exposure $(41 \%$ for externalising and $37 \%$ for internalising disorders). At the same time, these risk exposures significantly increased the odds of both externalising and internalising diagnoses, over and above the influence of maternal depression.

\section{Conclusions}

Children of clinically depressed mothers are exposed to both maternal psychopathology and risks that are associated with maternal mental health. These results may explain why treating mothers with depression shows beneficial effects for children, but does not completely neutralise the increased risk of psychopathology and impairment.

\section{Declaration of interest}

None.
Maternal depression is a significant public health concern because of its negative impact on both the mothers and their children. ${ }^{1}$ Rates of depression in women peak during pregnancy and in the early postnatal years. ${ }^{2}$ Although this is an established trend, depression is not randomly distributed across mothers; instead, previous studies suggest that compared with women who are not clinically depressed, depressed mothers are exposed to higher rates of cumulative life stressors including socioeconomic disadvantage, ${ }^{3}$ family violence and low social support, ${ }^{1}$ and they tend to follow riskier life-course pathways characterised by low educational attainment, teen pregnancy, substance use and criminal behaviours. ${ }^{4}$

The behaviour and life circumstances of an individual with depression can affect the lives of others around them. ${ }^{5}$ Maternal depression is thought to disrupt normative child development by impairing the ability of the mother to parent in a warm, consistent and sensitive manner. ${ }^{6}$ Indeed, it is well established that young children of mothers with depression are at increased risk for emotional problems, disruptive behaviours and attention and cognitive problems. ${ }^{4,7}$ Yet, to our knowledge, very few studies have examined the alternative explanation that psychopathology in the offspring of mothers with depression may in part be as a result of higher exposure to environmental, family and maternal risks. Research has suggested that children of mothers with depression may be exposed to a number of risks closely associated with maternal dysfunction ${ }^{8,9}$ - and that these risks may have equal or greater impact on early child psychopathology than depression in the mother. ${ }^{10-12}$ Moreover, although it has been reported that remission of a mother's major depression (after treatment) is significantly associated with reductions in her child's symptoms of psychopathology, these reductions were significantly less for children of mothers with depression who were experiencing the most severe environmental risks, and were less responsive to treatment. ${ }^{13}$ Hence, from a clinical perspective, risks associated with mental health in the mother may contribute to child psychiatric diagnosis, in addition to depression in the mother.

In the present research, we sought to examine, within a prospective epidemiological sample of 7429 mother-child pairs from varied socioeconomic and risk backgrounds, the predictive impact of maternal depression (child age, 1.5 years) and risk exposure of the child ( $0-2$ years) on the child's externalising and internalising DSM-IV-based ${ }^{14}$ diagnoses at 7.5 years. We focused on maternal depression and associated risks within the first few years of the child's life because during this age period the child is particularly dependent on the parenting and behaviour of the mother, ${ }^{15}$ which relates to achieving developmental milestones, such as cognitive maturation and development, and early social and emotional competence. ${ }^{16}$ We expected that exposure to risk factors associated with mental health in the mother would increase risk for child psychopathology above and beyond effects directly attributable to depression in the mother.

\section{Method}

\section{Sample}

The Avon Longitudinal Study of Parents and Children (ALSPAC) is an ongoing population-based study designed to investigate the effects of a wide range of influences on the health and development of children. Pregnant women resident in the former Avon Health Authority in southwest England, with an estimated date of delivery between 1 April 1991 and 31 December 1992, were 
invited to take part, resulting in a cohort of 14541 pregnancies and 13988 singletons/twins alive at 12 months of age. When compared with 1991 national census data, the ALSPAC sample was found to be similar to the UK population as a whole. ${ }^{16}$ Ethical approval for the study was obtained from the ALSPAC Law and Ethics Committee and the local research ethics committees. More detailed information on ALSPAC is available from the website: www.bris.ac.uk/alspac/.

\section{Measures}

Mothers completed questionnaires at multiple time points during their pregnancy and their child's infancy and childhood. The early risk factors examined here were drawn from questionnaires completed between birth and approximately 2 years of age. Our previous research has demonstrated the validity of the risks presented below. ${ }^{17,18}$

Descriptive statistics for the sample overall are presented in Table 1. The mother's ethnicity was recorded at 18 weeks' gestation. Child birth weight and birth complications (for example abruption, preterm rupture, cervical suture) were recorded at birth. Birth complications were dichotomised to contrast mothers with any complications (1) v. those without (0). Parity was obtained at 18 weeks' gestation from a series of questions about previous pregnancies. Multiparous mothers were coded 1 and primiparous mothers were coded 0 .

Maternal depression when the child was aged 21 months (1.5 years) was assessed with the Edinburgh Postnatal Depression Scale, a widely used 10-item self-report questionnaire that has been shown to be valid in and outside the postnatal period. ${ }^{19,20}$ A cut-off of 13 was used because it predicts a clinical diagnosis of depression. ${ }^{20}$ Nine per cent of the mothers included in this study ( $n=662$ of 7429 ) were identified as clinically depressed when the child was aged 1.5 years.

Environmental risk factors consisted of mother reports of low socioeconomic status (assessed at 18 weeks) and inadequate living conditions (assessed at 8 and 21 months). Poverty was coded via the Registrar General's social class scale; ${ }^{21}$ we compared mothers in classes IV and V (low socioeconomic status) with those in classes I, II and III. Inadequate living conditions were coded via any indication of not having a working bath/shower, no hot water, no indoor toilet and/or no working kitchen.

Family risk factors consisted of maternal reports of: (a) being a single caregiver (for example, not cohabiting, not in a relationship (assessed at 8 months)); (b) experiencing partner cruelty (for example, any indication of emotional and/or physical abuse from partner (assessed at 2, 6 and 21 months)); (c) low partner affection (for example, partner does not show affection, does not hug/kiss, low intimate bond (assessed at 8 months)); (d) low emotional support (for example, having no one to discuss feelings with (assessed at 2 and 8 months)); and (e) low practical support (i.e. whether there is anyone who could lend the mother $£ 100$ and/or the mother could turn to in times of trouble (assessed at 2 and 8 months)).

\section{Table 1 Sample characteristics and birth information}

\begin{tabular}{|lcc|}
\hline Variable & Statistic & $n / \mathrm{N}^{\mathrm{a}}$ \\
\hline Ethnicity, \% White & 95.7 & $7110 / 7429$ \\
\hline Multiparous, \% & 54.3 & $4036 / 7429$ \\
\hline Birth complications (at least 1), \% & 12.0 & $1109 / 5767$ \\
\hline Birth weight, g: mean (s.d.) & $3563.76(429.50)$ & 7429 \\
\hline Female children, \% & 49 & $3640 / 7429$ \\
\hline a. $n / \mathrm{N}=$ number of observations/total possible observations. & \\
\hline
\end{tabular}

Maternal lifestyle risk factors consisted of mother reports of: (a) early parenthood (19 years or younger (assessed at 18 weeks)); (b) low educational attainment (for example, did not finish mandatory schooling (assessed at 32 weeks prenatal)); (c) substance use (for example, any indication of the use of hard drugs, alcoholism, and/or consuming more than two pints of beer a day (assessed at 2, 8 and 21 months)); and (d) criminal trouble with police (any indication that this has happened (assessed at 2, 8 and 21 months)).

A cumulative risk index was created by summing the individual's risks described above (range 0-11). A cumulative risk index is consistent with the idea that: (a) although the effect of one risk might be weak, the effects of multiple risks can be quite large; and (b) because risks tend to cluster together, the number of risks, but not a particular risk, will explain greater variance in the adjustment outcome. ${ }^{22}$

At 7-8 years (7.5 years) DSM-IV psychiatric child diagnoses were measured using the Development and Well-Being Assessment (DAWBA), a well-validated measure developed for the British Child Mental Health surveys. ${ }^{23}$ The DAWBA generates preliminary DSM-IV psychiatric diagnoses for 5- to 17-year-olds using a well-defined computerised algorithm (see www.dawba. com) drawing on symptom reports from all available reporters. Experienced clinical raters then review all the data available for each child (including free-text comments made by respondents), and decide whether to accept or overturn the computer-generated diagnoses. Chance-corrected agreement between the two clinical raters who independently rated DAWBA data for 500 children in the first British Child Mental Health Survey was 0.86 for any disorder $($ s.e. $=0.04), 0.57$ for internalising disorders $($ s.e. $=0.11$ ) and 0.98 for externalising disorders $($ s.e. $=0.02){ }^{24}$

An adapted self-completion version of the DAWBA (including prompts for free-form comments) was devised for use in ALSPAC, and the clinical ratings were undertaken by the same two experienced clinicians as completed the ratings in the British national survey (Robert Goodman, who developed the DAWBA, and Tamsin Ford). For externalising disorders (reported by parents and teachers), we examined diagnoses of conduct disorder, oppositional defiant disorder and any attention-deficit hyperactivity disorder (ADHD) (including hyperactive, inattentive and combined subtypes, and ADHD not otherwise specified). With regard to internalising disorders (reported by parents), we used diagnoses of anxiety and depression.

\section{Attrition and missing data}

Of the original 14541 mothers, a total of 10141 mothers reported on their depression when their child was aged 1.5 years. Diagnostic DAWBA assessment was available for 8110 (externalising) and 8141 (internalising) children. A total of 7429 mothers had reports on depression and internalising disorders and the DAWBA diagnoses. In a multivariate logistic regression, we tested the study variables as predictors of exclusion $(n=7112) v$. inclusion $(n=7429)$. Odds ratios (ORs) showed that mothers excluded from the present analysis were more likely to currently have depression (OR $=1.22,95 \%$ CI $1.08-2.01)$, to be young mothers $(\mathrm{OR}=1.91,95 \% \mathrm{CI} 1.83-2.54)$, to have financial difficulties $(\mathrm{OR}=1.32,95 \% \mathrm{CI}=1.18-1.87)$, to have reported low partner affection $(\mathrm{OR}=1.65,95 \% \mathrm{CI} 1.42-1.92)$ and to have reported criminal trouble with the police $(\mathrm{OR}=1.51,95 \% \mathrm{CI}$ 1.05-2.23) than mothers included in the analyses. Their children were also more likely to have an externalising disorder $(\mathrm{OR}=1.70,95 \%$ CI $1.54-1.90)$. Of the 11 risks, 9 had minimal missing responses (i.e. $n=0-3)$, whereas substance use $(n=122)$ and partner affection $(n=443)$ showed higher rates. Missing data in substance use and partner affection, within the cumulative 
risk scale, were replaced by a imputation using an imputation procedure (PROC MI) in the statistical software SAS version 9.1 for Windows $7 .^{25}$

\section{Analysis}

The analysis proceeded in two main steps. In the first step, we compared the children of mothers with and without depression on exposure to each risk factor. We also verified that early maternal depression was associated with increased odds of externalising (i.e. ADHD, oppositional defiant disorder, conduct disorder) and/or internalising (anxiety, depression) disorders. In the second step, to maximise power, we collapsed ADHD, oppositional defiant disorder and conduct disorder into 'any externalising diagnosis', and anxiety and depression into 'any internalising diagnosis'. We then examined: (a) the effect of maternal depression alone; and (b) the reduction in the effect of maternal depression when controlling for cumulative risk as well as the independent effect of risk. The cumulative risk index was treated as continuous in this analysis, and the significance of the reduction in risk for a child psychiatric diagnosis was assessed with Sobel's test. ${ }^{26}$ The percentage decrease in the odds ratio was computed as:

$$
\frac{\left(\mathrm{OR}_{\text {uncorrected }}-\mathrm{OR}_{\text {corrected }}\right)}{\left(\mathrm{OR}_{\text {uncorrected }}-1\right) \times 100 \%}
$$

Analyses were conducted in SAS version 9.1. Odds ratios from logistic regressions are reported in the Results.

\section{Results}

\section{Step 1: maternal depression, risk factors exposure} and psychiatric disorders in the child

Table 2 shows the rates of risk-factor exposure in children of mothers with and without depression. Children of currently clinically depressed mothers were significantly more likely to be exposed to 10 of the 11 risk factors, compared with their counterparts with non-depressed mothers. Table 2 also contains the cumulative risk index (i.e. the sum of all risk factors). The difference in exposure to cumulative risks for the children of depressed $v$. non-depressed mothers was large. On average, children of depressed mothers were exposed to 2.3 risk factors, whereas children of non-depressed mothers were exposed to 1 risk factor.

Table 2 also shows the extent to which maternal depression (compared with mothers without depression) was associated with an increase in the odds of diagnoses of ADHD, oppositional defiant disorder, conduct disorder, anxiety and/or depression in children. Maternal depression increased the odds of all diagnoses. We note here, however, that the base rates for conduct disorder and depression were low.

\section{Step 2: the effect of maternal depression with and without controlling for the cumulative risk index}

Table 3 contains the effect of maternal depression on diagnoses of externalising and internalising disorder, with and without controlling for the cumulative risk index as a covariate. Maternal depression increased the odds of both externalising and internalising disorders (step 1 in Table 3). When the cumulative risk index was added to the equation (step 2), the impact of maternal depression was significantly reduced (i.e. $41 \%$ reduction for externalising and $37 \%$ reduction for internalising disorders). Yet, both exposure to maternal depression and exposure to the cumulative risks remained significant predictors of increased odds of both externalising and internalising disorder in the child (see step 2).

\section{Discussion}

\section{Main findings}

Using a large longitudinal cohort, we provide evidence that psychopathology in the offspring of clinically depressed mothers

\section{Table 2 Maternal depression (when child aged 1.5 years), risk exposure and child psychiatric diagnoses}

\begin{tabular}{|c|c|c|c|c|}
\hline \multirow[b]{2}{*}{ Type of risk } & \multicolumn{2}{|c|}{ Maternal depression } & \multirow[b]{2}{*}{ Difference, OR (95\% Cl) } & \multirow[b]{2}{*}{ Effect size } \\
\hline & Depressed & Not depressed & & \\
\hline \multicolumn{5}{|l|}{ Risk variable, \% (n) } \\
\hline \multicolumn{5}{|l|}{ Environmental risks } \\
\hline Low socioeconomic status & $34.4(227)$ & 12.9 (873) & $3.53^{*}(2.97-4.22)$ & \\
\hline Inadequate living conditions & $5.1(34)$ & 4.5 (304) & $1.15(0.80-1.66)$ & \\
\hline \multicolumn{5}{|l|}{ Family risks } \\
\hline Single caregiver & $12.7(687)$ & $10.2(84)$ & $1.29 *(1.01-1.64)$ & \\
\hline Partner cruelty & $38.8(257)$ & $11.3(764)$ & $4.99 *(4.19-5.93)$ & \\
\hline Low partner affection & $36.6(216)$ & 11.9 (759) & $4.28 *(3.56-5.14)$ & \\
\hline Low emotional support network & $38.1(252)$ & $10.3(698)$ & $5.34 *(4.49-6.37)$ & \\
\hline Low practical support network & $23.3(154)$ & $9.0(611)$ & $3.06 *(2.51-3.73)$ & \\
\hline \multicolumn{5}{|l|}{ Maternal lifestyle risks } \\
\hline Early parenthood (<20 years) & $6.5(43)$ & $4.2(285)$ & $1.58 *(1.14-2.20)$ & \\
\hline Low educational attainment & $13.5(87)$ & $10.8(719)$ & $1.19 *(1.01-1.63)$ & \\
\hline Substance use & $19.4(128)$ & $12.0(814)$ & $1.76 *(1.43-2.16)$ & \\
\hline Criminal trouble with police & $7.4(49)$ & $3.1(175)$ & $2.47 *(1.79-3.41)$ & \\
\hline \multicolumn{5}{|l|}{ Cumulative risk index, mean (s.d.) } \\
\hline Child age (0-2 years) & $2.31(1.72)$ & $0.99(1.25)$ & & $0.88^{\mathrm{a}}$ \\
\hline \multicolumn{5}{|l|}{ Child psychiatric diagnosis (age 7.5), \% (n) } \\
\hline Attention-deficit hyperactivity disorder & $4.5(27)$ & $1.7(121)$ & $2.81 *(1.86-4.24)$ & \\
\hline Oppositional defiant disorder & $4.1(19)$ & $1.8(95)$ & $2.31 *(1.52-3.56)$ & \\
\hline Conduct disorder & $2.2(14)$ & $0.4(28)$ & $4.52 *(2.72-9.90)$ & \\
\hline Anxiety & $7.7(51)$ & $2.6(174)$ & $3.16 *(2.29-4.37)$ & \\
\hline Depression & $1.2(8)$ & $0.4(24)$ & $3.44^{*}(1.54-7.68)$ & \\
\hline \multicolumn{5}{|c|}{$\begin{array}{l}\text { OR, odds ratio. } \\
\text { a. The resulting effect size is based on Cohen's } d \text { statistic, which represents the effect size difference in the mean number of risks experienced by depressed } v \text {. non-depressed } \\
\text { mothers. This statistic (0.88) is a large effect size, as interpreted using Cohen's }{ }^{27} \text { guidelines: an effect of } 0.20 \text { is a small effect, an effect of } 0.50 \text { is a medium effect, and an effect } \\
\text { of } 0.80 \text { is a large effect. } \\
{ }^{*} P<005 \text {. }\end{array}$} \\
\hline
\end{tabular}




\begin{tabular}{|c|c|c|c|}
\hline Predictor variable & OR $(95 \% \mathrm{Cl})$ & $P$ & $\begin{array}{l}\text { Comparison of OR for maternal } \\
\text { depression with and without } \\
\text { cumulative risk factors }\end{array}$ \\
\hline \multicolumn{4}{|l|}{ Externalising diagnosis } \\
\hline Step 1: depression at 1.5 years, without age $0-2$ cumulative risk & $2.56(1.88-3.49)$ & $<0.0001$ & \multirow{3}{*}{$41.0 \%$ decrease in $\mathrm{OR}^{\mathrm{a}}$} \\
\hline Step 2: depression at 1.5 years, with age $0-2$ cumulative risk & $1.92(1.38-2.67)$ & 0.0001 & \\
\hline Step 2: age 0-2 cumulative risk & $1.23(1.14-1.32)$ & $<0.001$ & \\
\hline \multicolumn{4}{|l|}{ Internalising diagnosis } \\
\hline Step 1: depression at 1.5 years, without age $0-2$ cumulative risk & $3.11(2.27-4.427)$ & $<0.0001$ & \multirow{3}{*}{$37.0 \%$ decrease in $\mathrm{OR}^{\mathrm{b}}$} \\
\hline Step 2: depression at 1.5 years, with age $0-2$ cumulative risk & $2.33(1.64-3.27)$ & 0.002 & \\
\hline Step 2: age 0-2 cumulative risk & $1.23(1.13-1.34)$ & & \\
\hline
\end{tabular}

is influenced by additional risk exposures closely associated with maternal mental health. More specifically, the present study underscores that, in addition to the debilitating effects of depression in the mother, multiple risk exposures strongly affect child psychopathology - with exposure to each additional risk factor there was at least a $20 \%$ increase in the odds for externalising and internalising disorders in boys and girls (Table 3). For example, a child with three risk factors increased their odds for a disorder by approximately $80 \%$ (i.e. $1.20 \times 1.20 \times 1.20)$. These epidemiological data suggest that addressing both maternal depression and associated risk factors may be the most effective manner by which to prevent adverse outcomes in the offspring, and that studies that consider the effect of maternal depression may benefit from also considering other risk factors associated with the mother's mental health.

As stated, few published research efforts have examined the degree to which additional risk exposures have an impact on child psychopathology above the influence of depression in the mother. Three studies ${ }^{9-11}$ reported that multiple contextual risks (for example, low social support, family conflict) had as large an effect on psychopathology in the child as did depression in the mother. However, this research was generally limited by small sample sizes and low rates of contextual risks, such as poverty, housing inadequacy, single motherhood, teen motherhood and criminal lifestyles. In addition, they typically did not examine clinical levels of child psychopathology. The present research supports and extends these earlier findings through examining a similar research question in a prospective epidemiological birth cohort of 7429 mother-child pairs from varied socioeconomic and risk backgrounds; and by assessing the predictive impact of maternal depression (when child aged 1.5 years) and risk exposure of the child (at 0-2 years) on the child's externalising and internalising DSM-IV-based diagnoses at 7.5 years.

Both the present study and the former studies, ${ }^{10}$ however, are correlational and were not designed to examine the reasons underlying the overlap of maternal depression with risk factors. For example, risk factors could cause depression in the mother, but depression and risk could also work in a bidirectional manner, whereby increases in one relate to increases in the other, thereby increasing child exposure to both maternal psychopathology and risks associated with mental health in the mother. ${ }^{28}$ There is, however, growing evidence from natural experiments, randomised controlled trials and other statistically innovative designs that both maternal depression and contextual risk factors such as poverty have causal effects on children's mental health. ${ }^{13,29}$ In future, studies of these kinds could be used to test whether some risk factors have a greater effect than others on child and maternal mental health. For example, it may be that proximal risk factors (e.g. family violence) have a stronger effect on child psychopathology than distal risk factors (e.g. poverty). In the present study, however, we examined a cumulative risk factor, where all risks were equally weighted.

In addition, the present results also help to validate findings that programmes that successfully intervene on maternal depression are also associated with improvements - but generally not complete remission - in adverse child outcomes. ${ }^{13,30,31}$ For example, certain associated risk factors may be more responsive to intervention than others - targetable risks include trying to increase social support network density and to decrease maternal alcohol use and dysfunction in the family. The risk of poverty, which is robustly associated with adverse child outcomes, ${ }^{32}$ on the other hand, has been shown to be less responsive to intervention (see, for example, Kling et al), ${ }^{33}$ but can be successfully buffered by attentive parents who are actively involved in their child's life. ${ }^{34}$ Hence, interventions aimed at reducing depression in the mother and its adverse effects on the children likely need to be informed by the nature of specific risks, their respective impacts on the child and how they may directly or indirectly respond to an intervention.

Incomplete intervention effects on the child may also be related to at least two developmental sources: (a) the timing of the exposures; and (b) the reciprocal relationships between the mother and the child. With regard to the timing of exposures, the emergence of risk factors in certain periods of development may influence and change a child's developmental pathway. In the present study, we assessed risk exposure from birth to 2 years of age, a critical developmental period when, for example, brain maturation (i.e. the hippocampus), mother-child attachment and the foundations of cognitive and socioemotional competence are in play. ${ }^{35}$ Early disturbances in normative development can have lasting effects on child well-being. ${ }^{29}$ With regard to reciprocal effects, the relationship between maternal depression and child disturbance appears to be bidirectional, such that the child's problems can contribute to the mother's symptoms which then, in turn, can further increase the child's problems. ${ }^{36}$ If such reciprocal patterns are established early in the life course, an intervention focused on the child, as well as the mother, is likely to be necessary.

\section{Limitations}

The present results should be interpreted in the context of seven main limitations. First, as stated, this research is correlational in nature, hence no causative relationships have been identified. Second, most measures were based on maternal reports, raising the possibility of shared method variance. Future studies should 
incorporate multiple informants. Third, we relied on self-reports of clinically depressed mothers, which calls into question the accuracy of the reports. That said, studies have found that mothers with depression can be as accurate as other informants about their children's behaviour ${ }^{37}$ and a recent meta-analyses suggested that the size of the effect of maternal depression on child outcomes, as measured by maternal reports on scale formats $v$. clinical diagnoses, do not significantly differ. ${ }^{38}$ Fourth, although the mothers and children of ALSPAC represent a broad spectrum of socioeconomic backgrounds, the sample includes relatively low rates of individuals from ethnic minorities. The present results will need replication with more ethnically diverse samples. Fifth, like most large longitudinal cohorts, ALSPAC has faced attrition over time. As expected, younger and more socially disadvantaged mothers were more likely to be lost to follow-up. However, although attrition affected prevalence rates of depression in the mother and the externalising and internalising disorders in the children, previous studies have suggested that the associations between risks and outcomes remained intact, although conservative estimates, of the likely true effects. ${ }^{39}$ Sixth, we focused on maternal depression and associated risks in the early postnatal period. Earlier (prenatal effects) and later mother, child- and family-based risks may also contribute to differentiating and maintaining early psychopathology in the child, and are important targets for future study. Seventh, in addition to maternal depression, paternal psychopathology has been shown to negatively affect child development. ${ }^{9}$ Future research should examine the additive and interactive effects of psychopathology from the mother and father on child well-being.

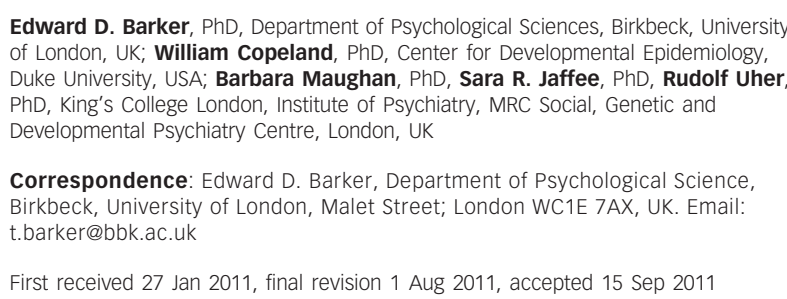

\section{Funding}

The UK Medical Research Council, the Wellcome Trust and the University of Bristol provide core support for ALSPAC. B.M. is supported by the Medical Research Council.

\section{Acknowledgements}

We are extremely grateful to all the families who took part in this study, the midwives for their help in recruiting them, and the whole ALSPAC team, which includes interviewers, computer and laboratory technicians, clerical workers, research scientists, volunteers, computer and laboratory technicians,

\section{References}

1 Goodman SH, Gotlib IH. Risk for psychopathology in the children of depressed parents: a developmental approach to the understanding of mechanisms. Psychol Rev 1999; 106: 458-90.

2 Kessler RC. Epidemiology of women and depression. J Affect Disord 2003; 74: 5-13.

3 Pickett KE, Wilkinson RG. Inequality: an underacknowledged source of mental illness and distress. Br J Psychiatry 2010; 197: 426-8.

4 Kim-Cohen J, Moffitt TE, Taylor A, Pawlby SJ, Caspi A. Maternal depression and children's antisocial behavior: nature and nurture effects. Arch Gen Psychiatry 2005; 62: 173-81.

5 Hammen C, Burge D, Adrian C. Timing of mother and child depression in a longitudinal study of children at risk. J Consul Clin Psychol 1991; 59: 341-5.
6 Hammen C, Burge D, Stansbury K. Relationship of mother and child variables to child outcomes in a high-risk sample: a causal modeling analysis. Dev Psychol 1990; 26: 24-30.

7 Brennan PA, Hammen C, Andersen MJ, Bor W, Najman JM, Williams GM. Chronicity, severity, and timing of maternal depressive symptoms: relationships with child outcomes at age 5. Dev Psychol 2000; 36 759-66

8 Jaffee SR, Belsky J, Harrington H, Caspi A, Moffitt TE. When parents have a history of conduct disorder: how is the caregiving environment affected? J Abnorm Psychol 2006; 115: 309-19.

9 Brennan PA, Hammen C, Katz AR, Le Brocque RM. Maternal depression, paternal psychopathology, and adolescent diagnostic outcomes. J Consult Clin Psychol 2002; 70: 1075-85.

10 Cicchetti D, Rogosch FA, Toth SL. Maternal depressive disorder and contextual risk: contributions to the development of attachment insecurity and behavior problems in toddlerhood. Dev Psychopathol 1998; 10: 283-300.

11 Ashman SB, Dawson G, Panagiotides H. Trajectories of maternal depression over 7 years: relations with child psychophysiology and behavior and role of contextual risks. Dev Psychopathol 2008; 20: 55-77.

12 Dawson G, Ashman SB, Panagiotides H, Hessl D, Self J, Yamada E, et al. Preschool outcomes of children of depressed mothers: role of maternal behavior, contextual risk, and children's brain activity. Child Dev 2003; 74 1158-75.

13 Weissman MM, Pilowsky DJ, Wickramaratne PJ, Talati A, Wisniewski SR Fava $\mathrm{M}$, et al. Remissions in maternal depression and child psychopathology. JAMA 2006; 295: 1389-98.

14 American Psychiatric Association. Diagnostic and Statistical Manual of Mental Disorders (4th edn) (DSM-IV). APA, 1994.

15 Jaffee SR. Sensitive, stimulating caregiving predicts cognitive and behavioral resilience in neurodevelopmentally at-risk infants. Dev Psychopathol 2007; 19: $631-47$

16 Shonkoff JP, Boyce WT, McEwen BS. Neuroscience, molecular biology, and the childhood roots of health disparities: building a hew framework for health promotion and disease prevention. JAMA 2009; 301: 2252-9.

17 Barker ED, Oliver BR, Maughan B. Co-occurring problems of early onset persistent, childhood limited, and adolescent onset conduct problem youth. I Child Psychol Psychiatry 2010; 51: 1217-26.

18 Barker ED, Maughan B. Differentiating early-onset persistent versus childhood-limited conduct problem youth. Am J Psychiatry 2009; 166: 900-8.

19 Cox JL, Holden JM, Sagovsky R. Detection of postnatal depression. Development of the 10-item Edinburgh Postnatal Depression Scale. Br J Psychiatry 1987; 150: 782-6.

20 Murray L, Carothers AD. The validation of the Edinburgh Post-natal Depression Scale on a community sample. Br J Psychiatry 1990; 157 288-90.

21 Office of Population Censuses and Surveys. Standard Occupational Classification (Vol 3). HMSO, 1991.

22 Sameroff A. Environmental risk factors in infancy. Pediatrics 1998; 102: 1287-92.

23 Meltzer H, Gatward R, Goodman R, Ford F. Mental health of children and adolescents in Great Britain. TSO (The Stationery Office), 2000

24 Ford T, Goodman R, Meltzer H. The British Child and Adolescent Mental Health Survey 1999: the prevalence of DSM-IV disorders. J Am Acad Child Adolesc Psychiatry 2003; 42: 1203-11.

25 SAS Institute. SAS/STAT User's Guide, Version 9.1 (4th edn). SAS Institute, 2005

26 MacKinnon DP, Lockwood CM, Hoffman JM, West SG, Sheets V. A comparison of methods to test mediation and other intervening variable effects. Psychol Methods 2002; 7: 83-104.

27 Cohen J. Statistical Power Analysis for the Behavioral Sciences (2nd edn). Lawrence Erlbaum, 1988.

28 Dohrenwend B, Levav I, Shrout P, Schwartz S, Naveh G, Link B, et al Socioeconomic status and psychiatric disorders: the causation-selection issue. Science 1992; 255: 946-52.

29 Costello EJ, Compton SN, Keeler G, Angold A. Relationships between poverty and psychopathology. JAMA 2003; 290: 2023-9.

30 Garber J, Ciesla JA, McCauley E, Diamond G, Schloredt KA. Remission of depression in parents: links to healthy functioning in their children. Child Dev 2011; 82: 226-43.

31 Gunlicks ML, Weissman MM. Change in child psychopathology with improvement in parental depression: a systematic review. J Am Acad Child Adolesc Psychiatry 2008; 47: 379-89. 
32 Ingoldsby $E$, Shaw $D$, Winslow $E$, Schonberg $M$, Gilliom M, Criss $M$. Neighborhood disadvantage, parent-child conflict, neighborhood peer relationships, and early antisocial behavior problem trajectories. J Abnorm Child Psychol 2006; 34: 293-309.

33 Kling JR, Ludwig J, Katz LF. Neighborhood Effects on Crime for Female and Male Youth: Evidence from a Randomized Housing Voucher Experiment. Working Paper No 10777. National Bureau of Economic Research, 2004 (http://www.nber.org/papers/w10777).

34 Barker ED, Trentacosta CJ, Salekin RT. Are impulsive adolescents differentially influenced by the good and bad of neighborhood and family. J Abnorm Psychol 2011; May 9 (Epub ahead of print)

35 Lupien SJ, McEwen BS, Gunnar MR, Heim C. Effects of stress throughout the lifespan on the brain, behaviour and cognition. Nat Rev Neurosci 2009; 10 434-45.
36 Gross HE, Shaw DS, Moilanen KL, Dishion TJ, Wilson MN. Reciprocal models of child behavior and depressive symptoms in mothers and fathers in a sample of children at risk for early conduct problems. J Fam Psychol 2008; 22: $742-51$

37 Richters JE. Depressed mothers as informants about their children: a review of evidence for distorion. Psychol Bull 1992; 112: 485-99.

38 Goodman S, Rouse M, Connell A, Broth M, Hall C, Heyward D, Materna depression and child psychopathology: a meta-analytic review. Clin Child Fam Psychol Rev 2011; 14: 1-27.

39 Wolke D, Waylen A, Samara M, Steer C, Goodman R, Ford T, et al. Selective drop-out in longitudinal studies and non-biased prediction of behaviour disorders. Br J Psychiatry 2009; 195: 249-56.

\section{poems by doctors}

\section{S.O.A.P}

\section{Ron Charach}

To document the progress of patients today's intern uses the format

Subjective, Objective, Assessment, Plan: S.O.A.P.

Case in point: a long-haired, bespectacled man

brought in at midnight to Emerg.

Subjective; "I'm the lowest of the low." (Long pause.)

"That's it. that's all you need to know."

Objective: Pale, disheveled middle-aged Caucasian male lacking I.D.

Expressionless. Paucity of movement, speech.

No evidence of vis./audit. hallucinations.

Assessment: Major depression.

Rule out head trauma, schizophrenia, dementia.

Plan: Re-assess when more able to communicate.

Suicide watch. Vitals Q2H.

Blood work to rule out organicity.

Attempt to locate family.

The method organizes thought

- though at first I balked at making SOAP

from the boiling pot of human woes.

Profound depressions all look the same.

As I probe this man's good vein

he holds his arm out

like a branch that ends in his hand,

gazing ahead, as in a dream.

"Next week," I answer, "things will be different.

Your sadness is confusing you."

But his expression remains the same.

That's it. Nothing more,

though much more I need to know.

Ron Charach took his medical degree at the University of Manitoba, Canada. He trained in psychiatry in Toronto and New York, and has lived in Toronto since 1980. Dr Charach is the author of nine books of poetry and the non-fiction book Cowboys and Bleeding Hearts: Essays on Violence, Health and Identity. This poem is from his new volume of poetry Forgetting the Holocaust, published in Calgary, Alberta, by the Frontenac House (2011). Ron Charach.

Chosen by Femi Oyebode. 